\title{
Intramolecular Hetero-Diels-Alder Reaction of Prolinal-Derived N-Arylimines Lewis Acid-Dependent Reversal of the Diastereoselectivity
}

Frank Linkert, Sabine Laschat*

Organisch-Chemisches Institut der Universităt Münster, Corrensstr. 40, 48149 Münster, Germany

Received 15 November 1993

Abstract: Intramolecular Lewis acid-catalyzed hetero-Diels-Alder reaction of L-prolinal-derived $\mathrm{N}$-arylimine 1 yielded diastereoselectively either the cis, cis-diazacyclopenta[a]anthracene derivative 2 a or the trans,trans-isomer $\mathbf{2 b}$, depending on the Lewis acid.

From a synthetic point of view the Diels-Alder reaction seems to be one of the most powerful reactions for the formation of $\mathrm{C}-\mathrm{C}$ bonds. ${ }^{1}$ Especially the hetero-Diels-Alder reaction gives rise to a broad range of heterocyclic systems. ${ }^{2}$ Various imines were used in such reactions both as dienophiles and dienes. However, previous studies on $\mathbf{N}$ arylimines as 2-azadienes reported mainly their reactions with electronrich dienophiles.3,4 In this context, we recently published an intramolecular Lewis acid-catalyzed cyclization of citronellal-derived $\mathrm{N}$-arylimines, which results in the formation of octahydroacridines in high yields and good diastereoselectivity.5 This cyclization can be treated formally as a hetero-Diels-Alder reaction with the N-arylimine as the 2-azadiene moity beeing tethered to a non-activated dienophile.

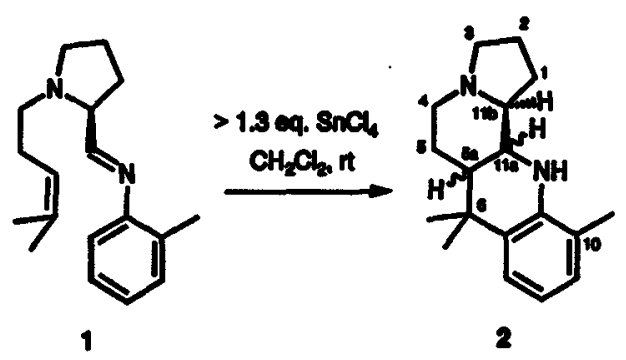

We here report on a related intramolecular Lewis acid-catalyzed hetero-Diels-Alder reaction of the prolinal-derived $\mathrm{N}$-arylimine 1 towards decahydro-3a,11-diazacyclopenta[a]anthracene 2. Contrary to the citronellal-derived arylimines, where the cis/trans ratio was strongly controlled by the substitution pattern in the $\beta$-position (relative to the imino group) of the cyclization precursor and only to a minor extent by the Lewis acid, the diasterecselectivity in the cyclization of 1 can be completely controlled by the suitable choice of the Lewis acid.

In a typical experiment a solution of (-)(S)-N-[N-(4-methyl-3pentenyl)pyrrolidine-2-methylidene]toluidine 1 6,7 in $\mathrm{CH}_{2} \mathrm{C}_{2}$ was treated with $\mathrm{SnCl}_{4}(2.5$ eq.) at room temperature for $42 \mathrm{~h}$ and the resulting (11b-S)-6,6,10-trimethyl-1,2,3,4,5,5a,6,11a,11b-decahydro3a,11-diazacyclopenta[a]anthracene 2 was isolated after basic hydrolysis with $2 \mathrm{~N} \mathrm{NaOH}$ as a mixture of the cis,cis isomer $2 \mathrm{a}$ and the trans,trans isomer $2 \mathrm{~b}$ (cis/trans $=1: 99)^{8}$ in $82 \%$ yield. No traces of the remaining two diastereomers $2 c$ and $2 d$ could be detected by capillary GC of the crude products. As shown in Table $I$ the cyclization can be achieved with different Lewis and Brönsted acids
Table I. Cyclization of $\mathrm{N}$-prolinal-imine 1 in the presence of different Lewis acids

\begin{tabular}{|c|c|c|c|c|c|}
\hline Entry & Lewis acid & Eq. & $\begin{array}{l}\text { Temp. } \\
{\left[{ }^{\circ} \mathrm{C}\right]}\end{array}$ & $\begin{array}{c}2 a: 2 b^{a} \\
\text { all-cis : all-trans }\end{array}$ & $\begin{array}{l}\text { Yield b } \\
\text { [\%] }\end{array}$ \\
\hline (1) & $\mathrm{FeCl}_{3}$ & 2.0 & It & $16: 84$ & 80 \\
\hline (2) & $\mathrm{SnC}_{4}$ & 2.5 & rt & $1: 99$ & 82 \\
\hline (3) & $\mathrm{SnCl}_{4}$ & 2.5 & -40 & $1: 99$ & 81 \\
\hline (4) & $\mathrm{SnCl}_{4}$ & 2.5 & -78 & $3: 97$ & 87 \\
\hline (5) & $\mathrm{BF}_{3} \cdot \mathrm{OEt}_{2}$ & 2.0 & rt & $2: 98$ & 81 \\
\hline (6) & $p$-TsOH & 1.5 & $\mathbf{r t}$ & $6: 94$ & 82 \\
\hline (7) & TFA & 1.5 & rt & $13: 87$ & 79 \\
\hline (8) & $\mathrm{AlC}_{3}$ & 2.5 & $\mathbf{r t}$ & $5: 95$ & 79 \\
\hline (9) & $\mathrm{BtAlCl}_{2}$ & 1.3 & $\mathbf{r t}$ & $99: 1$ & 83 \\
\hline (10) & $\mathrm{EtAlCl}_{2}$ & 2.5 & -78 & $15: 85$ & 83 \\
\hline (11) & $\mathrm{Et}_{2} \mathrm{AlC}$ & 2.5 & $\mathrm{rt}$ & $3: 97$ & 81 \\
\hline (12) & $\mathrm{MeAlCl}_{2}$ & 1.3 & rt & $99: 1$ & 84 \\
\hline (13) & $\mathrm{MeAlC}_{2}$ & 1.3 & -78 & $89: 11$ & 82 \\
\hline (14) & $\mathrm{Me}_{2} \mathrm{AlCl}$ & 1.5 & It & $96: 4$ & 79 \\
\hline
\end{tabular}

a) All reactions were run in $\mathrm{CH}_{2} \mathrm{C}_{2}$ for $42 \mathrm{~h}$; cis/trans ratios were determined by capillary $\mathrm{GC}$ of the crude products.

b) Yields of isolated major diastereomer.

with good to excellent diastereoselectivities. In all studied cases at least a stoichiometric amount of the Lewis acid is required to achieve the cyclization. 9 Best results concerning the cis/prans selectivity were obtained by using 1.3 - 2.5 equivalents of the acidic catalyst. However the most remarkable result was the dependency of the cis/trants ratio on the type of Lewis acid. Whereas $\mathrm{FeCl}_{3}, \mathrm{SnCl}_{4}, \mathrm{BF}_{3}-\mathrm{OEt}_{2}, p-\mathrm{TsOH}$, TFA, $\mathrm{AlCl}_{3}$ and $\mathrm{Et}_{2} \mathrm{AlCl}$ yielded almost exclusively the trans product $2 b$ (entries $1,2,5-8,11$ ), the ratio was completely reversed in favour of the cis product 2a, when $\mathrm{BtAlCl}_{2}, \mathrm{MeAlC}_{2}$ and $\mathrm{Me}_{2} \mathrm{AlCl}$ (entries 9, $12,14)$ were used. It was also found, that in the case of $\mathrm{EAAlCl}_{2}$ the cis/trans ratio was reverted by lowering the reaction temperature from room temperature (cis/trans $=99: 1)$ to $-78^{\circ} \mathrm{C}$ (cis/trans $=16: 84$ ) (entries 9,10). On the contrary, $\mathrm{SnCl}_{4}$ and $\mathrm{MeAlC}_{2}$ showed no such temperature-dependent reversal (entries $2-4,12,13$ ).

In order to explain the diastereoselectivity, we consider four possible transition state geometries, which are favoured by different Lewis acids (Scheme I), mainly because of the different distances and dihedral angles between the nitrogen atoms displayed by the cyclization precursor 1.10 Thus exo-I shows a relatively small N-N distance and a 
concave geometry which should be favoured by small chelating Lewis acids, like tetrahedral ionic aluminum complexes, formed in situ from $\mathrm{EtAlC}_{2}, \mathrm{MeAlCl}_{2}$ and $\mathrm{Me}_{2} \mathrm{AlCl}$.11 The larger distance and almost antiperiplanar orientation of the two nitrogen atoms in endo-I should be favoured either by coordination of a monodentate Lewis acid $\left(\mathrm{BF}_{3} \cdot \mathrm{OE}_{2}\right)$, thus blocking the top face of the 2-azadiene, or by a larger, i.e. octahedral bidentate Lewis acid $\left(\mathrm{SnCl}_{4}\right)$. The remaining transition states (endo-II, exo-II) either seem to have N-N distances, which are too large for efficient chelation of Lewis acids, or the Lewis acid displays unfavourable steric interactions with the carbon tether, i.e. $\mathrm{C}(4), \mathrm{C}(5)$.

The different behaviour of $\mathrm{EtAlC}_{2}$ and $\mathrm{MeAlC}_{2} 12$ in determining the cis/trans ratio at various temperatures might be explained by an equilibrium between monomeric and dimeric alkylaluminum dichloride species, which results in the presence of different catalytic active species in solution depending on the temperature. Further investigations to explore the reaction, which seems to be a promising example for efficient stereocontrol in Lewis acid catalyzed cyclization
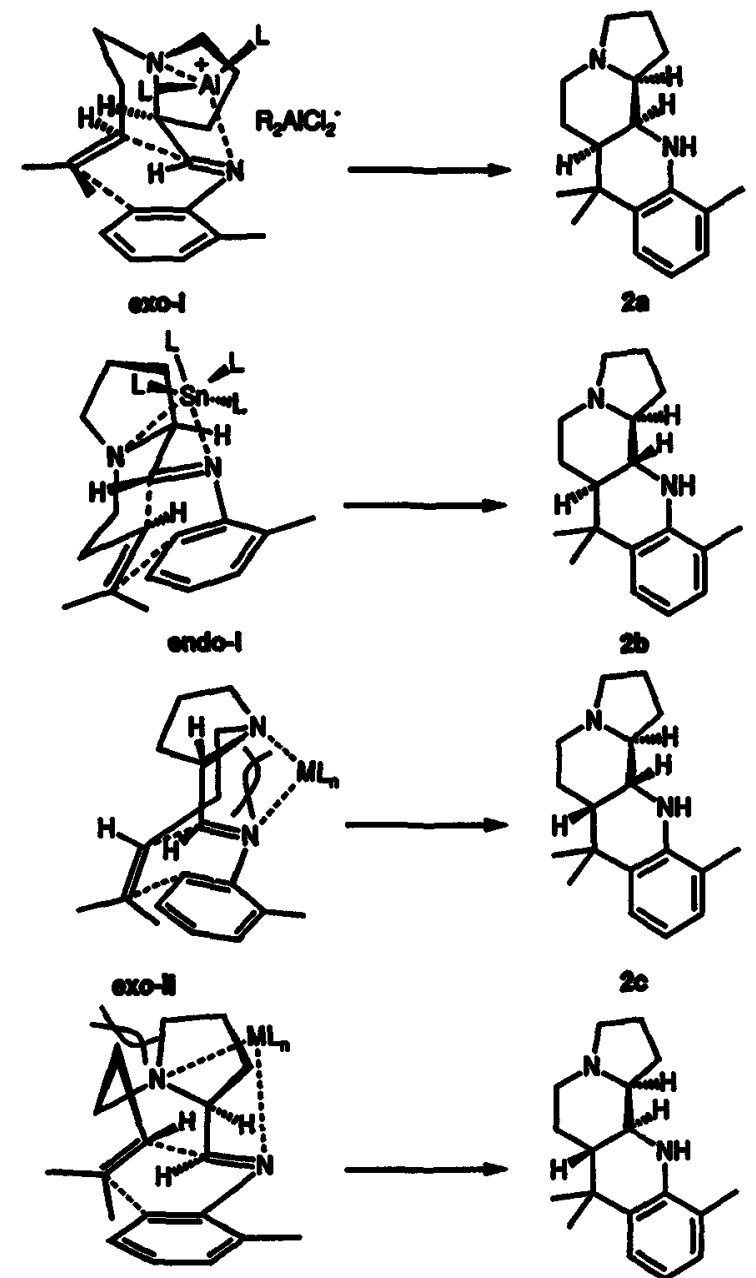

endorl

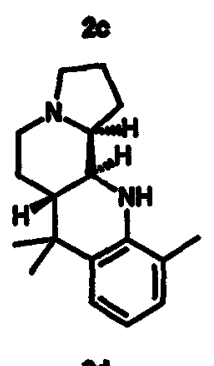

Scheme 1

reactions of imines by using the chelating ability of a second nitrogen atom, and especially the mechanism in more detail are now under way.

Acknowledgement. This work was supported by the Alfried Krupp von Bohlen und Halbach Stiftung. S. L. thanks the Wissenschaftsministerium Nordhein-Westfalen for a Lise-Meitner fellowship.

\section{References and Notes}

(1) Oppolzer, W. Angew. Chem. 1984, 96, 876; Angew. Chem. Int. Ed. Engl. 1984, 23, 876.

Taber, D. F. Intramolecular Diels-Alder and Alder Ene reactions, Springer Verlag: Berlin, 1984.

(2) Boger, D. L.; Weinreb, S. N. Hetero Diels-Alder Methodology in Organic Synthesis, Academic Press: New York, 1987; p 35.

(3) Intramolecular reactions of activated dienophiles tethered to the 2-azadiene: Weinreb, S. N. In Comprehensive Organic Symthesis, Vol. 5; Trost, B. M. (ed.); Pergamon Press: Oxford, 1991; p 402.

(4) Intramolecular reactions of non-activated dienophiles tethered to the 2-azadiene: Tietze, L. F.; Utecht, J. Chem. Ber. 1992, 125 , 2259.

(5) Laschat, S.; Lauterwein, J. J. Org. Chem. 1993, 58, 2856.

(6) The prolinal imine 1 was prepared through the following sequence: (L)-prolinol was N-alkylated with 4-methyl-3-pentenyl bromide in the presence of $\mathrm{K}_{2} \mathrm{CO}_{3}$ according to ref. (7). The resulting N-4-methyl-3-pentenyl-prolinol was then subjected to Swern oxidation to give the corresponding aldehyde, which was finally converted to the imine 1 by reaction with o-toluidine in the presence of molecular sieves $4 \AA$.

(7) Dike, S. Y.; Mahaligau, M.; Kumar, A. Tetrahedron Lett. 1990, 4641.

(8) The absolute configuration of cis,cis-2a and trans, trans-2b was established by NMR. The IH-NMR spectra ( $360 \mathrm{MHz}, \mathrm{CDCl}_{3}$ ) showed the following characteristic coupling pattem for H-11a: $\delta=3.73\left(\mathrm{dd}, \mathrm{J}_{11 \mathrm{a}, 11 \mathrm{~b}}=2.6 \mathrm{~Hz}, \mathrm{~J}_{11 \mathrm{a}, 5 \mathrm{a}}=2.5 \mathrm{~Hz}\right.$ ) in the spectrum of $2 \mathrm{a}$, and $\delta=3.00$ (ddd, $J_{11 a, 11 b}=9.5 \mathrm{~Hz}, J_{11 a, 5 a}=9.5 \mathrm{~Hz}$, $J_{11 a, N H}=1.0 \mathrm{~Hz}$ ) in the spectrum of $2 \mathrm{~b}$. This assignment was further confirmed by COSY and NOESY spectra.

(9) In nucleophilic additions to $\mathrm{N}$-glycosylimines a reversal of the diastereoselectivity was observed when 3-pyridylcarboxaldimine was used instead of benzaldimine (with $\mathrm{ZnCl}_{2}$ as Lewis acid in both cases). This was attributed to the complexation of a second Lewis acid molecule by the pyridine nitrogen, which results in a different coordination geometry in the transition state. $\mathrm{Kunz}, \mathrm{H}$;; Pfrengle, W. Angew. Chem. 1989, 101, 1041; Angew. Chem. Int. Ed. Engl. 1989, 28, 1067.

(10) The following approximate N-N distances and dihedral angles for N-C(11a)-C(11b)-N were calculated from molecular models: exo-I: $2.3 \AA, 120^{\circ}$; endo-I: $3.3 \AA, 180^{\circ}$; exo-II: $2.8 \AA, 60^{\circ}$; endo-II: $3.3 \AA, 180^{\circ}$. The terms exo and endo refer to the orientation of the $\mathrm{H}$-atom on the dienophile relative to the diene system.

(11) Mixed ionic aluminum species as Lewis acids in carbo-DielsAlder reactions: Evans, D. A.; Chapman, K. T.; Hung, T.; Kawaguchi, A. T. Angew. Chem. 1987, 99, 1197; Angew. Chem. Int. Ed. Engl. 1987, 26, 1184 and refs. cited therein.

(12) A different behaviour woncerning reactivity and/or selectivity of different alkylaluminum chloride species was already observed in ene reactions: Snider, B. B.; In Selectivities in Lewis Acid Promoted Reactions; Schinzer, D. Ed.; Kluwer Academic Publishers: Dordrecht, 1989; p 147. 